Indonesian Journal of
Mathematics and Natural Sciences Education
p-ISSN: 2721-172X e-ISN: 2721-1746
Vol. 1 No.3 Th 2020; hal 158 -164
http://mass.iain-jember.ac.id

\title{
Penerapan Joyful Learning Untuk Meningkatkan Hasil Belajar Mahasiswa Matakuliah Fisiologi Tumbuhan
}

\author{
Heni Setyawati \\ ${ }^{1}$ Prodi Tadris Biologi IAIN Jember, Jember, Indonesia. \\ * E-mail: henisetyawati0787@gmail.com
}

\begin{abstract}
Abstrak
Penelitian ini bertujuan untuk mendeskripsikan penerapan joyful learning terhadap hasil belajar mahasiswa pada mata kuliah fisiologi tumbuhan. Penelitian ini merupakan penelitian deskriptif kuantitatif. Pengumpulan data dalam penelitian menggunaan tes, observasi, dan dokumentasi. Data dianalisis dengan membandingkan nilai UTS fisiologi tumbuhan mahasiswa angkatan 2017 dengan nilai UTS fisiologi tumbuhan mahasiswa angkatan 2016. Hasil penelitian menunjukkan bahwa penerapan joyful learning dapat meningkatkan hasil belajar mahasiswa sebesar 32,67. Selain itu pembelajaran fisiologi tumbuhan dengan joyful learning dapat meningkatkan kualitas pembelajaran fisiologi tumbuhan yaitu meningkatkan kenyamanan mahasiswa selama pembelajaran, meningkatkan aktivitas mahasiswa dan meningkatkan minat mengikuti pembelajaran fisiologi tumbuhan.
\end{abstract}

Kata Kunci: joyful learning, hasil belajar.

\section{PENDAHULUAN}

Mata kuliah fisiologi tumbuhan merupakan mata kuliah wajib yang harus diambil oleh mahasiswa S1 jurusan/ program studi biologi maupun pendidikan biologi. Prodi Tadris Biologi IAIN Jember juga merupakan program studi yang mewajibkan mata kuliah fisiologi tumbuhan dalam kurikulum dan ditawarkan pada semester V. Berdasarkan hasil dokumentasi nilai UTS dan UAS mahasiswa angkatan 2015 dan 2016 diketahui bahwa hanya beberapa mahasiswa saja yang mampu mencapai capaian pembelajaran mata kuliah fisiologi tumbuhan. Dengan kata lain dapat diketahui bahwa hasil belajar mahasiswa Prodi Tadris Biologi dalam mata kuliah kuliah fisiologi tumbuhan masih tergolong rendah. Sehingga diperlukan upaya untuk mengatasinya.

Pembelajaran fisiologi tumbuhan selama ini diajarkan melalui metode ceramah. Hal ini dikarenakan materi banyak dan dikhawatirkan materi tidak tuntas serta mengantisipasi terjadi miskonsepsi. Hal tersebut disebabkan karena input mahasiswa prodi tadris biologi selama ini masih tergolong menengah kebawah. Metode ceramah mempunyai keuntungan materi cepat selesai. Namun demikian metode ceramah juga mempunyai kelemahan yaitu kurang mampu memberikan 
pengalaman belajar yang bervariasi dan mengaktifkan mahasiswa selama proses pembelajaran. Dengan demikian perlu dicoba dilakukan modifikasi pembelajaran. Salah satu metode pembelajaran yang dapat digunakan agar pembelajaran tidak monoton dan memberi wadah bagi aktivitas belajar siswa adalah metode joyful learning .

Joyful learning adalah pembelajaran menyenangkan yang bertujuan untuk menarik siswa agar fokus terhadap pembelajaran sehingga pembelajaran dirancang sedemikian rupa sehingga menimbulkan suasana tidak membosankan bagi siswa. Salirawati (2018) menyatakan bahwa untuk mengatasi pembelajaran yang monoton dan kejenuhan dapat melakukan pembelajaran dengan pendekatan Joyful learning. Joyful learning membuat siswa tertekan, takut salah, dan ditertawakan. Penyampaian materi pembelajaran secara menyenangkan telah tercantum dalam UU No.20 Tahun 2003 tentang sistem pendidikan nasional pasal 40 yang menyatakan bahwa pendidik berkewajiban dapat menciptakan suasana pembelajaran bermakna, menyenangkan dan kreatif.

Selama proses pembelajaran, siswa perlu merasa senang dan bahagia dalam mempelajari sesuatu. Joyful learning mampu membentuk mental sehat dan membuat lingkungan belajar menjadi menyenangkan, akibatnya siswa dapat menikmati pembelajaran sehingga tercipta pembelajaran yang bermakna bagi siswa. Peran guru dalam Joyful learning adalah menciptakan lingkungan pembelajaran yang mendukung ditambah penggunaan berbagai media pembelajaran. Dengan demikian Joyful learning akan dapat meningkatkan potensi diri siswa secara optimal (Bhakti dkk, 2018).

Setiap pendidik harus memahami cara menyampaikan materi kepada siswa dengan banyak variasi (Rudduck \& Flutter, 2004). Dengan menerapkan joyful learning siswa mampu merasakan kenyamanan sehingga dapat menikmati skenario pembelajaran yang telah dirancang pendidik. Joyful learning memberikan pengalaman belajar siswa untuk mampu mengembangkan minat belajar dan karena pembelajaran didesain dinamis, menarik sehingga pembelajaran tidak monoton. Dengan demikian joyful learning berpengaruh besar dalam meningkatkan prestasi belajar siswa (Permatasari dkk., 2014).

Lebih lanjut Salirawati (2018) menjelaskan bahwa semua mahasiswa mengharapkan semua dosen melakukan pembelajaran dengan joyful learning, sehingga mahasiswa akan merasa lebih termotivasi selama pembelajaran dan materi dapat lebih mudah dipahami. Adapun hasil wawancara Salirawati (2018) terhadap mahasiswa prodi kimia menunjukkan bahwa 55\% mahasiswa menyatakan sangat penting dan $45 \%$ menyatakan penting untuk dilakukan selingan dan humor pada pembelajaran. Bentuk-bentuk joyful learning anatara lain melalui lagu, permainan, drama, penayangan film, outdoor activity, peraga, diskusi, dan mengaitkan materi dengan kehidupan sehari-hari. Penelitian ini bertujuan untuk mengetahui penerapan joyful learning terhadap hasil belajar mahasiswa tadris biologi pada mata kuliah fisiologi tumbuhan. 
Indonesian Journal of Mathematics and Natural Science Education, 1 (3), 2020

Heni Setyawati

\section{METODE}

Penelitian ini merupakan penelitian deskriptif kuantitatif. Penelitian dilakukan pada bulan AgustusOktober 2019. Teknik pengumpulan data dalam penelitian menggunakan tes, observasi, dan dokumentasi. Observasi digunakan untuk mengetahui respon siswa selama pembelajaran. Dokumentasi dilakukan untuk mendokumentasikan proses pembelajaran, sementara tes digunakan untuk mengetahui hasil belajar mahasiswa.

Subjek penelitian meliputi seluruh mahasiswa tadris biologi angkatan 2017 yang mengambil matakuliah fisiologi tumbuhan pada semester gasal tahun ajaran 2019/2020 yang berjumlah 82 mahasiswa. Tes dilakukan pada saat UTS (Ujian tengah semester). Analisis data dilakukan dengan membandingkan rata-rata nilai UTS fisiologi tumbuhan angkatan 2017 dengan angkatan 2016.

\section{HASIL DAN PEMBAHASAN}

Pelaksanaan joyful learning selama penelitian dilakukan secara umum dilakukan melalui tahapan berikut :
a. Membuka pembelajaran dengan doa
b. Menyanyikan lagu kebangsaan
c. Apersepsi penyampaian materi
d. Penayangan video pembelajaran
e. Game
f. Diskusi materi
g. Menutup materi dengan doa

$$
\text { Selain tahapan tersebut }
$$

pembelajaran juga dilakukan melainkan dikombinasi dengan teknik-teknik yang lain agar pembelajaran benar-benar terjadi dalam suasana yang menyenangkan sesuai dengan kaidah Joyful Learning. Kombinasi teknik pembelajaran yang telah dilakukan antara lain: diskusi, presentasi hasil diskusi, role playing, dan outdoor learning. Output kegiatan pembelajaran joyful learning disajikan pada beberapa foto pembelajaran sebagai berikut :

a. Diskusi

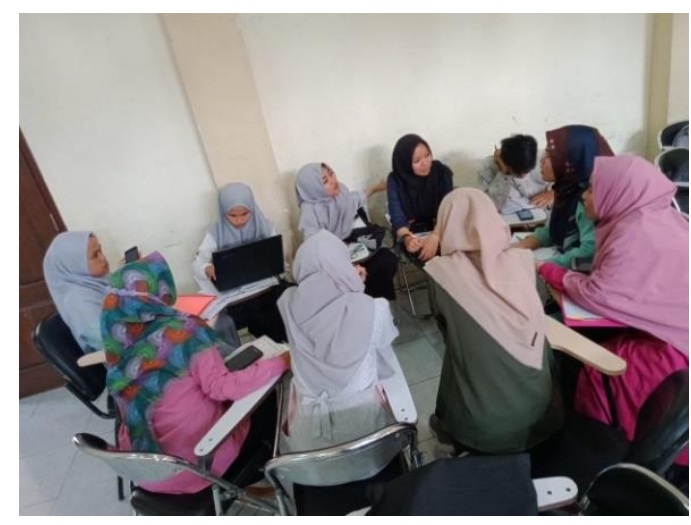

Gambar 1 Mahasiswa sedang melakukan diskusi kelompok

b. Presentasi hasil diskusi

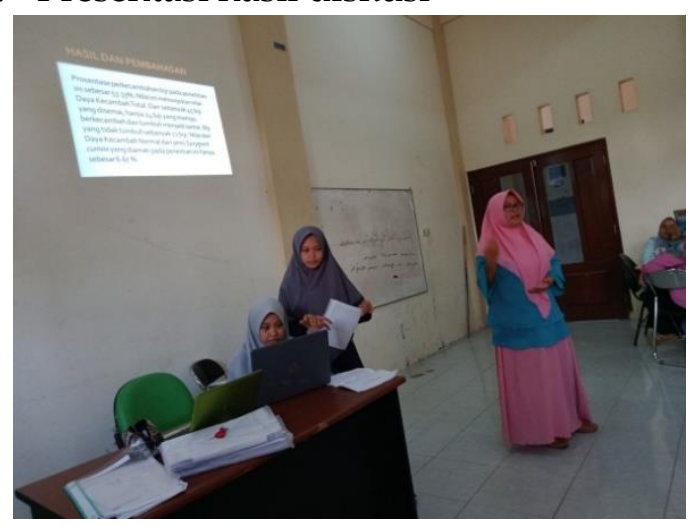

Gambar 2 Mahasiswa sedang presentasi hasil diskusi kelompok

c. Role playing

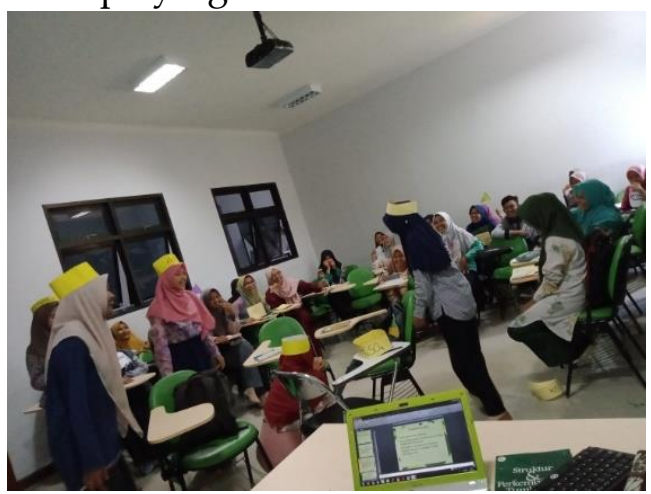

Gambar 3.a Mahasiswa melalukan role playing didepan kelas 


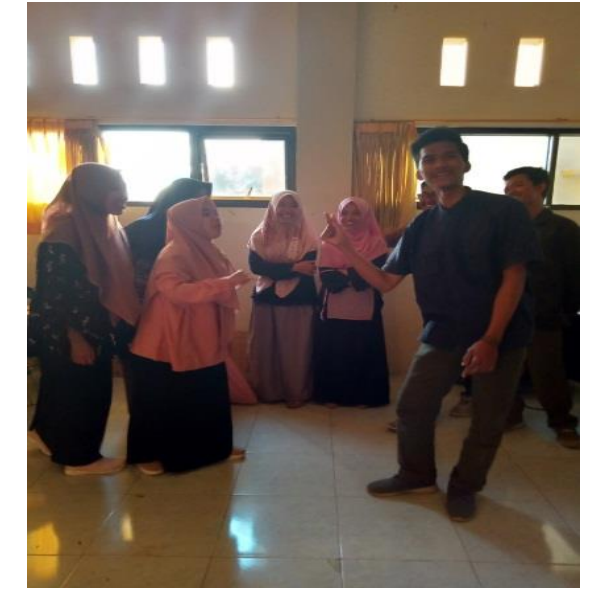

Gambar 3.b Mahasiswa melalukan role playing didepan kelas

d. Outdoor activity

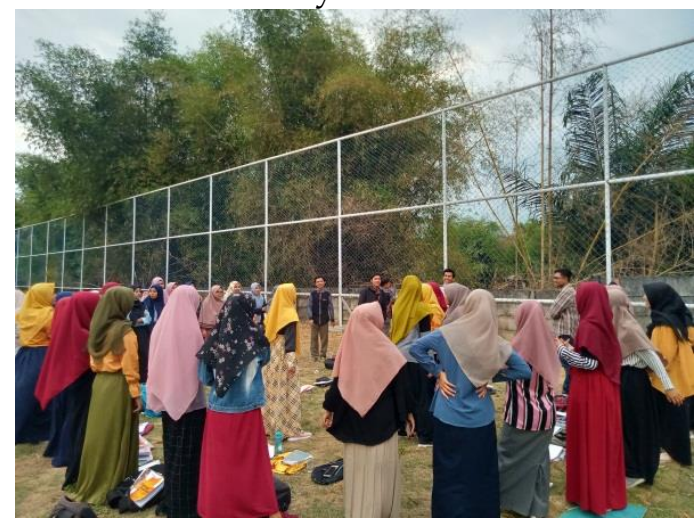

Gambar 4.a Mahasiswa melakukan pembelajaran di luar kelas

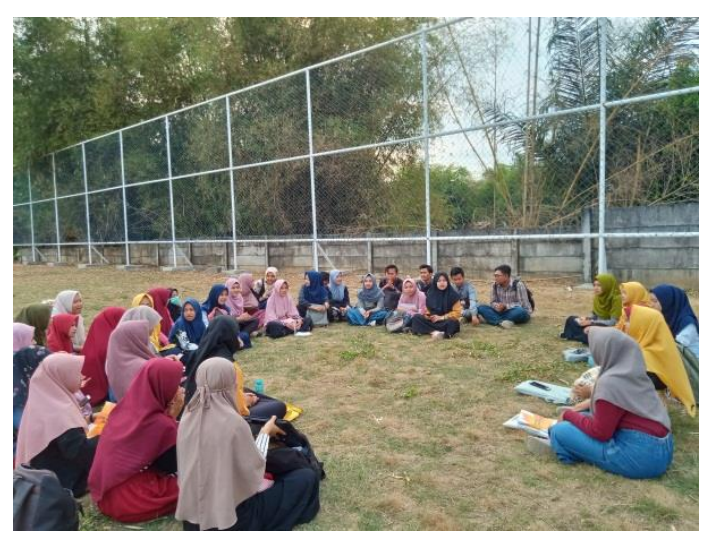

Gambar 4.b Mahasiswa melakukan pembelajaran di luar kelas

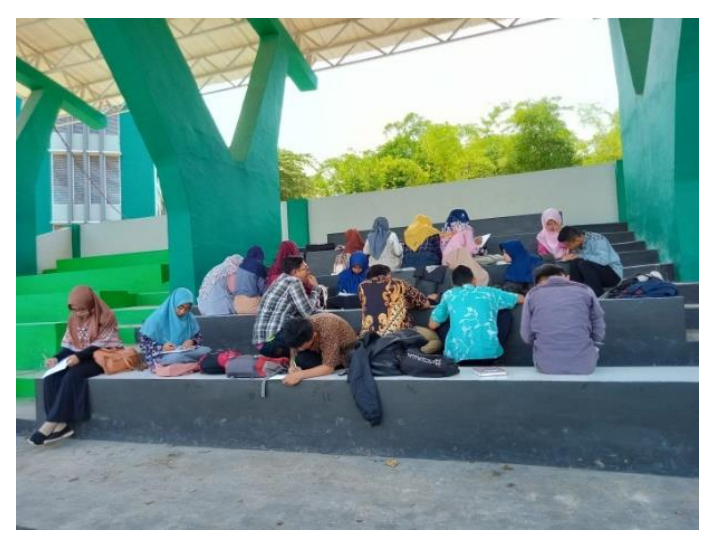

Gambar 4.c Mahasiswa melakukan pembelajaran di luar kelas

Berdasarkan gambar 1, 2, 3,dan 4 dapat diketahui bahwa pembelajaran tersebut mengaktifkan siswa. Hasil observasi menunjukkan bahwa seluruh siswa antusias selama pembelajaran, tidak ada mahasiswa yang terlambat, serta mahasiswa terlihat tidak jenuh dan tidak mengantuk. Selama pembelajaran mahasiswa sering terlihat tertawa lepas. Hal ini sesuai dengan teori yang diungkapkan oleh seorang kardiolog Universitas Maryland, Michael Miller menganjurkan bahwa siswa yang mempunyai permasalahan, hendaknya dilakukan treatment yang mampu memberikan kesempatan untuk dapat tertawa lepas. Karena saat tertawa tubuh mampu menghasilkan tiga senyawa yang menyebabkan rasa senang, nyaman, yaitu endorfin, melatonin dan serotonin (Safri, 2005). Hal ini juga sejalan dengan hasil penelitian Bhakti dkk.(2018) yang menyatakan bahwa kebahagiaan pada saat belajar dapat membuat manusia mampu mencapai potensi optimalnya.

Hasil penilaian hasil belajar menunjukkan bahwa nilai rata-rata UTS fisiologi tumbuhan angkatan 2017 sebesar 32,67 , sementara nilai rata-rata UTS angkatan 2017 sebesar 53,25, 
berdasarkan data tersebut maka dapat diketahui bahwa hasil belajar fisiologi tumbuhan meningkat dengan dilakukan serangkaian kegiatan aktualisasi. Perbandingan hasil UTS angkatan 2016 dan 2017 disajikan sebagai berikut:

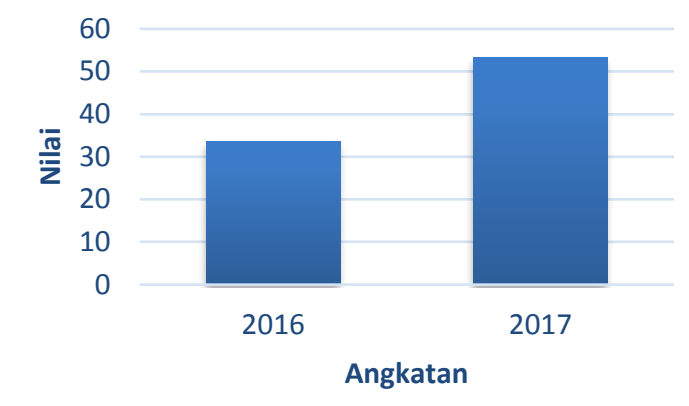

Gambar 5. Perbandingan hasil UTS angkatan 2016 dan 2017

Berdasarkan gambar 5 dapat diketahui bahwa penerapan Joyful learning terbukti dapat meningkatkan hasil belajar mahasiswa. Terjadi peningkatan sejumlah 20,58. Hal ini sesuai hasil penelitian yang dilakukan oleh Istiani dkk.(2014) yang menyatakan bahwa pembelajaran menggunakan joyful learning berpengaruh signifikan terhadap hasil belajar dan termasuk kategori berpengaruh kuat.

Model pembelajaran joyful learning merupakan salah satu alternatif model pembelajaran yang diharapkan mampu mencipkatan situasi belajar yang menyenangkan dan aktif melibatkan siswa dalam pembelajaran namun tanpa beban. Pengalaman belajar dirancang agar dapat membuat siswa merasakan kenikmaatan selama pembelajaran berlangsung. Joyful learning mampu membantu siswa untuk mengem-bangkan kemampuan berpikir, membangun konsep sendiri da mampu merumuskan kesimpulan serta menghadapkan siswa padalam situasi pembelajaran menyenangkan, dengan demikian siswa akan menyukai materi yang dibelajarkan. Pembelajaran dirancang dinamis dengan menekankan hal-hal visual serta menyenangkan. Joyful learning derdampak besar pada prestasi siswa. Pembelajaran Joyful learning menekankan pada belajar sambil melakukan (learning by doing). (Permatasari, 2014). Materi pelajaran kan lebih mudah diterima siswa apabila siswa memiliki keaktian dan rasa ingin tahu yang tinggi sehingga siswa mendominasi aktivitas pembelajaran. Siswa dapat menemukan ide pokok materi, memecahkan masalah dan mengaplikasikan apa yang mereka pelajari ke dalam kehidupan nyata.

Hasil penelitan juga selaras dengan teori yang dikemukakan oleh Slavin (2005) bahwasannya joyful learning merupakan metode pembelajaran yang menyenangkan sehingga selama pembelajaran siswa akan menikmati pembelajaran karena siswa merasa nyaman dan mengasikkan. Pembelajaran joyful learnin mengandung unsur "inner motivation"yakni dorongan dari dalam diri untuk senantiasa merasa ingin tahu sehingga akan menyebabkan usaha untuk mencari tahu. Dampak posistifnya yaitu mampu membuat siswa merasa senang terhadap proses pembelajaran. Hasil penelitian Dewi (2017) menyatakan bahwamenyebutkan bahwa pada pembelajaran Joyful learning menyebakan siswa tidak merasa tertekan dan menikmati proses pembelajaran, sehingga membantu dapam pencapaian hasil belajar.

Wills (2011) mengungkapkan bahwa berdasarkan penelitian otak, jika kenyamanan dan kesenangan dihapuskan dan digantikan dengan homo-genitas, dan ketika spontanitas digantikan 
dengan kepatuhan pada perintah, otak siswa dijauhkan dari pemrosesan informasi dan penyimpanan jangka panjang yang efektif. Berdasarkan studi pencitraan syaraf, kenyamanan siswa sangat berdampak pada pemindahan dan penyimpanan informasi di dalam otak. Rasa senang dan gembira siswa berdampak pada tubuh untuk melepaskan endorfin, epineferin (adrenalin), serta dopamin, dan meningkatkan volume oksigen dalam proses pernapasan. Saat siswa belajar dalam lingkungan belajar yang diperkaya dan dengan stimulus indra yang beragam maka siswa akan lebih fokus dengan lebih banyak kesempatan untuk terhubung secara personal dan interpersonal dengan materi yang disampaikan dan merasa bahwa informasi tersebut berkaitan dengan kehidupan sehari-hari.

Semakin banyak macam model pembelajaran yang diterapkan selama pembejaran mengakibatkan terbentuknya jalur-jalur dendritik yang semakin banyak. Dengan demikian akan lebih banyak jembatan penghubung sinaptik dari sel ke sel. Penyampaikan informasi secara visual akan membentuk hubungan dengan loba-loba normal occipital. Selanjutnya dengan membuat siswa mendengar informasi secara berkesinambungan menyebabkan terkaitnya sirkuit dendritik dengan loba temporal, akibatnya akses otak terhadap informasi yang tersimpan akan lebih cepat (Anggoro, 2014).

\section{SIMPULAN}

Joyful learning dapat meningkatkan hasil belajar mahasiswa sebesar 32,67. Selain itu pembelajaran fisiologi tumbuhan dengan joyful learning dapat meningkatkan kualitas pembelajaran fisiologi tumbuhan yaitu meningkatkan kenyamanan mahasiswa selama pembelajaran, meningkatkan aktivitas mahasiswa dan meningkatkan minat mengikuti pembelajaran fisiologi tumbuhan.

\section{DAFTAR PUSTAKA}

Anggoro, S.(2014). Pendekatan Joyfull Learning Pada Proses Pembelajaran di Sekolah Dasar (Kajian Teoritis dan Neurosains). https://www.researchgate.net/publ ication/318471313. Diakses 28 Agustus 2020.

Bhakti, C.P., Ghiffari, M.A.N. \& Salsabil, K. (2018). Joyful Learning: Alternative Learning Models to Improving Student's Happiness. Jurnal Varidika .Volume 30. No. 2. http://journals.ums.ac.id/index.ph $\mathrm{p} /$ varidika/article/view/7572

Dewi, S. (2017). Perbandingan Hasil Belajar Siswa Melalui Strategi Pembelajaran Joyfull Learning dan Every One Is A teacher Here Kelas X Teknik Sepeda Motor dan Kelas $X$ Teknik Gambar Bangunan Pada Materi Termodinamika SMKN 1 Sulawesi Selatan Tahun Ajaran 2016/2017. (2017). Skripsi. Fakultas Tarbiyah dan Keguruan UIN Alaudin Makasar.

Istiani, Y., Imron, A., \& Arif, S. (2014). Pengaruh Model Pembelajaran Joyful Learning terhadap Hasil Belajar Siswa. Jurnal Pendidikan dan Penelitian Sejarah. Vol2, No.4. http://jurnal.fkip.unila.ac.id/index. 
php/PES/article/view/5983. diakses 20 Juli 2020.

Jumroh, J \& Winarti, D. (2016). Penerapan Pembelajaran Joyful Learning dengan Menggunakan Multimedia Interaktif di SMA Karya Ibu Palembang. Wahana Didaktika Vol 14.No.1. https://jurnal.univpgripalembang.ac.id/index.php/didakt ika/article/view/570. Diakses 20 Juli 2020.

Permatasari, A.I., Mulyani, B. \& Nurhayati, N.D. (2014). Efektivitas Penggunaan Model Pembelajaran Joyful Learning dengan Metode Pemberian Tugas terhadap Prestasi Belajar Siswa pada Materi Pokok Koloid Siswa Kelas XI IPA SMA Negeri 1 Simo Tahun Pelajaran 2012/2013. Jurnal Pendidikan Kimia (JPK). Vol 3No.1. https://media.neliti.com/media/pu blications/125668-ID-none.pdf. Diakses 20 Juli 2020.

Rudduck, J \& Flutter,J. (2004). How to Improve Your School. New York: Continuum.
Safri, H. S. (2005). Tertawa itu Sehat. Yogyakarta: Pustaka Pelajar.

Salirawati, D. (2018). Pentingnya Penerapan Joyful Learning dalam Penciptaan Suasana Belajar yang Menyenangkan.

http://staffnew.uny.ac.id/upload/1 32001805/penelitian/14-makalahjoyful-learning.pdf. Diakses 20 Juli 2020

Slavin, R.E. (2005). Cooperative Learning (Cara Efektif dan Menyenangkan Pacu Prestasi Seluruh Peserta Didik. Bandung: Nusa Media.

Willis, Judy. (2011). Understanding How the Brain Thinks.: http://www.edutopia.org/blog/will is judemd/Understanding How $\mathrm{t}$ he Brain Thinks. Diakses 30 Agustus 2020.

\section{PROFIL SINGKAT}

Penulis lahir di Kabupaten Sleman, DIY pada tanggal 29 Juli 1987. Penulis merupakan pengajar di program studi tadris biologi IAIN Jember sejak tahun 2016 hingga sekarang. 